\title{
Total loss of MHC class $I$ is an independent indicator of good prognosis in breast cancer
}

\author{
Zahra Madjd ${ }^{1}$, Ian Spendlove ${ }^{1}$, Sarah E. Pinder ${ }^{2}$, Ian O. Ellis ${ }^{3}$ and Lindy G. Durrant ${ }^{1 *}$ \\ ${ }^{1}$ Cancer Research UK Academic Unit of Clinical Oncology, Nottingham City Hospital, United Kingdom \\ ${ }^{2}$ Histopathology, Addenbrooke NHS Trust, Cambridge, United Kingdom \\ ${ }^{3}$ Department of Histopathology, City Hospital, Nottingham, United Kingdom
}

\begin{abstract}
Tumours can be recognised by CTL and NK cells. CTL recognition depends on expression of MHC Class I loaded with peptides from tumour antigens. In contrast, loss of MHC Class I results in NK activation. In our study a large set of samples from patients with primary operable invasive breast cancer was evaluated for the expression of MHC Class I heavy and light by immunohistochemical staining of $\mathbf{4 3 9}$ breast carcinomas in a tissue microarray. Forty-seven percent (206 of 439) of breast carcinomas were considered negative for HLA Class I heavy chain (HC10), whereas lack of anti- $\beta_{2}$ m-antibody staining was observed in $39 \%$ (167 of 424) of tumours, with only $3 \%$ of the $\beta_{2} m$-negative tumours expressing detectable HLA Class I heavy chain. Correlation with patient outcome showed direct relationship between patient survival and HLA-negative phenotype $(\log r a n k=0.004)$. A positive relationship was found between the intensity of expression of MHC Class I light and heavy chains expression and histological grade of invasive tumour $(p<\mathbf{0 . 0 0 1})$ and Nottingham Prognostic Index $(p<0.001)$. To investigate whether HLA Class I heavy and light chains expression had independent prognostic significance, Cox multivariate regression analysis, including the parameters of tumour size, lymph node stage, grade and intensity of HC10 and anti- $\beta_{2} \mathrm{~m}$ staining, was carried out. In our analysis, lymph node stage $(p<0.001)$, tumour grade $(p=0.005)$ and intensity of MHC Class I light and heavy chains expression were shown to be independent prognostic factors predictive of overall survival ( $p$-values HC10 $=0.047$ and $\beta_{2} \mathrm{~m}=0.018$ ).

(C) 2005 Wiley-Liss, Inc.
\end{abstract}

Key words: breast tissue microarray; $\mathrm{HC} 10$; prognostic factor; $\mathrm{MHC}$ Class I; immunohistochemistry

Tumours may either fail to stimulate an immune response a process known as immune ignorance ${ }^{1}$ or they may elicit innate or adaptive immunity in a process known as immune editing. ${ }^{2}$ Major histocompatibility complex (MHC) may play a pivotal role in immune-editing as they present peptides that are recognised by cytolytic T cells. In contrast, if MHC antigens are downregulated to avoid T cell attack they become susceptible to NK killing.

There are 4 altered HLA Class I phenotypes that are found commonly in tumour tissues including: phenotype I or total HLA loss $(9-52 \%)$ that result from interference with $\beta_{2} \mathrm{~m}$ synthesis transporter associated with antigen processing (TAP) or structural defects in MHC genes; phenotype II or loss of HLA haplotype that can result from chromosomal nondisjunction or mitotic recombination; phenotype III or loss of HLA locus expression e.g., HLAA (3-19\%); and HLA-B (5-19\%), probably with a mechanism of transcriptional. Phenotype IV or HLA allelic loss (15-51\%) that such allelic loss might result from mutations or partial deletions of HLA Class I genes.

Previous studies have demonstrated that HLA Class I antigens are downregulated in tumour tissues of patients diagnosed as having breast carcinomas. ${ }^{4-9}$ MHC alterations on the cell surface of tumours may be an early event or the effect of a multi-step process during carcinogenesis. ${ }^{10}$ Moreover, loss of expression of MHC Class I antigens is observed commonly in malignant tumours ${ }^{3,11}$ and has been considered one of the mechanisms for escape from cytotoxic T cells. ${ }^{12}$ Some rare tumour types, however, have shown increased expression of HLA Class I, particularly those derived from tissues with weak or normal HLA Class I expression. ${ }^{11}$ Few studies have examined the prognostic significance of HLA Class I expression in cancer. In those studies, loss of HLA Class I molecules has been associated with poor degree of differentiation, aggressiveness and metastatic potential. ${ }^{8,9,11,13,14}$ To our knowledge, however, there has been no previous study examining whether there is any prognostic significance of HLA Class I loss on a large number of paraffin embedded invasive breast carcinomas. To analyse haplotype or allelic loss on paraffin sections of tumours it would be necessary to know the HLA type of all of the patients. This is not possible, however, in a retrospective study as many of these patients are no longer alive. In contrast, antibodies to polymorphic heavy chains and $\beta_{2} \mathrm{~m}$ are available allowing us to study complete loss of MHC Class I.

To obtain more insight into the prognostic value and mechanisms that tumour cells use to escape from immune system, we analysed HLA Class I expression in a large series of breast cancer tissue arrays using a monoclonal antibody to the polymorphic heavy chain $(\mathrm{HC} 10)$ and a polyclonal anti- $\beta_{2}$ microglobulin antibody. Expression of HLA heavy and light chains was then associated with various clinicopathological parameters and patient outcome. Our study group consisted of 439 primary operable breast cancer with a mean follow up of 7 years.

\section{Material and methods \\ Patients and tumour characteristics}

The original study group consisted of 439 primary operable invasive breast carcinoma from patients $27-70$ years of age (median $=54$ years) diagnosed between 1987-1992 and obtained from the Nottingham Tenovus Primary Breast Carcinoma Series. Patient characteristics, including age and menopausal status, were also collected and information on local, regional and distant recurrence and survival was also retrieved from a prospective database (Table I). Patients were followed up at 3-month intervals initially, then 6-month intervals, then annually for a median period of 83 months with a mean survival of 77 months (1-151 months).

Patient management was based on tumour characteristics by calculating the Nottingham Prognostic Index (NPI). Women with an NPI score $\leq 3.4$ received no adjuvant therapy, those with a NPI score $>3.4$ received tamoxifen if ER positive ( \pm Zoledex if premenopausal) or classical cyclophosphamide, methotrexate and 5-fluorouracil (CMF) if ER negative and fit enough for chemotherapy to be appropriate.

\section{Tissue preparation}

Breast cancer tissue microarrays were prepared as described previously. ${ }^{15}$ Each case was sampled in 3 copies, each containing one sample from a different region of the tumour. ${ }^{16}$ Specimens

Grant sponsor: Iranian Ministry of Health and Medical Education.

The first two authors contributed equally to this manuscript.

*Correspondence to: CRUK Academic Unit of Clinical Oncology, City Hospital, Hucknall Road, Nottingham, NG5 1PB, UK.

Fax: +0115-9628033, +0115-9627923.

E-mail: lindy.durrant@nottingham.ac.uk

Received 7 December 2004; Accepted after revision 18 February 2005

DOI 10.1002/ijc. 21163

Published online 17 May 2005 in Wiley InterScience (www.interscience. wiley.com). 
TABLE I - CORRELATION OF HLA EXPRESSION IN INVASIVE BREAST CARCINOMA WITH CLINICOPATHOLOGICAL PARAMETERS (PEARSON $\chi^{2}$ )

\begin{tabular}{|c|c|c|c|c|c|}
\hline \multirow[t]{2}{*}{ Tumour and patient characteristics } & \multirow[t]{2}{*}{ Proportion \% $(n)$} & \multicolumn{2}{|c|}{$\begin{array}{c}\text { Intensity of staining } \\
\text { (p-value) }\end{array}$} & \multicolumn{2}{|c|}{$\begin{array}{l}\text { Percentage of cells stained } \\
(p \text {-value })\end{array}$} \\
\hline & & $\mathrm{HC} 10$ & Anti- $\beta_{2} \mathrm{~m}$ & $\mathrm{HC} 10$ & Anti- $\beta_{2} \mathrm{~m}$ \\
\hline $\begin{array}{c}\text { Age (years) } \\
<40 \\
41-50 \\
51-60 \\
>61\end{array}$ & $\begin{array}{c}8(39) \\
28(150) \\
36(193) \\
28(151)\end{array}$ & 0.452 & 0.19 & 0.072 & 0.341 \\
\hline $\begin{array}{l}\text { Menopausal status ( } \% \text { of recorded cas } \\
\text { Pre-menopausal } \\
\text { Post-menopausal }\end{array}$ & $\begin{array}{l}36(184 / 507) \\
64(322 / 507)\end{array}$ & 0.567 & 0.765 & 0.625 & 0.266 \\
\hline $\begin{array}{l}\text { Histological Grade } \\
\text { Grade } 1 \\
\text { Grade } 2 \\
\text { Grade } 3\end{array}$ & $\begin{array}{l}21(111) \\
35(186) \\
44(236)\end{array}$ & $<0.001$ & $<0.001$ & $<0.001$ & $<0.001$ \\
\hline $\begin{array}{l}\text { Lymph node status } \\
\text { LN negative } \\
\text { LN positive }\end{array}$ & $\begin{array}{l}64(340) \\
36(193)\end{array}$ & 0.223 & 0.145 & 0.682 & 0.216 \\
\hline $\begin{array}{l}\text { Tumour size }(\mathrm{mm}) \\
\quad<10,11-20,21-30,31-40,41-50 \\
\mathrm{NPI}^{2}\end{array}$ & $\mathrm{NA}^{1}$ & 0.285 & 0.197 & 0.464 & 0.093 \\
\hline $\begin{array}{l}\text { Good } \\
\text { Moderate } \\
\text { Poor }\end{array}$ & $\begin{array}{l}35(181) \\
55(285) \\
10(55)\end{array}$ & $<0.001$ & $<0.001$ & $<0.001$ & 0.003 \\
\hline $\begin{array}{l}\text { Tumour type } \\
\text { Excellent } \\
\text { Good } \\
\text { Moderate } \\
\text { Poor }\end{array}$ & $\begin{array}{l}6(31) \\
21(113) \\
12(64) \\
61(325)\end{array}$ & $<0.001$ & $<0.001$ & $<0.001$ & $<0.001$ \\
\hline $\begin{array}{l}\text { Vascular invasion } \\
\text { None or probable } \\
\text { Definite }\end{array}$ & $\begin{array}{l}71(370) \\
29(154)\end{array}$ & 0.615 & 0.149 & 0.515 & 0.3 \\
\hline $\begin{array}{l}\text { Distant metastases } \\
\text { Absent } \\
\text { Present }\end{array}$ & $\begin{array}{l}88(470) \\
12(63)\end{array}$ & 0.027 & 0.028 & 0.045 & 0.032 \\
\hline $\begin{array}{l}\text { Any recurrence } \\
\text { Absent } \\
\text { Present }\end{array}$ & $\begin{array}{l}77(409) \\
23(124)\end{array}$ & 0.242 & 0.141 & 0.214 & 0.1 \\
\hline $\begin{array}{l}\text { Regional recurrence } \\
\text { Absent } \\
\text { Present }\end{array}$ & $\begin{array}{c}91(484) \\
9(49)\end{array}$ & 0.007 & 0.017 & 0.018 & 0.028 \\
\hline $\begin{array}{l}\text { Local recurrence } \\
\text { Absent } \\
\text { Present }\end{array}$ & $\begin{array}{l}90(480) \\
10(53)\end{array}$ & 0.885 & 0.545 & 0.268 & 0.616 \\
\hline Overall survival & - & 0.004 & 0.021 & 0.004 & 0.072 \\
\hline
\end{tabular}

${ }^{1}$ NA, none applicable. ${ }^{2}$ NPI (The Nottingham Prognostic Index) is an integrated prognostic index used to predict patient survival for women with invasive breast cancer based on tumour size, lymph node stage and tumour grade. It is often clinically utilised in three groups: good ( $\leq 3.4)$, moderate $(3.41-5.4)$, and poor prognosis $(>5.4)-{ }^{3}$ Tumour sections were classified in four prognostic type groups as described previously. ${ }^{36}$ Excellent prognosis type ( $>80 \%$ 10-year survival) includes tubulo-lobular, tubular, mucinous and invasive cribriform carcinoma. Good prognosis types (60-80\% 10-year survival) includes tubular mixed, mixed ductal with special type and alveolar lobular carcinoma. Moderate prognosis types (50-60\% 10-year survival) includes classical lobular, medullary, atypical medullary and lobular mixed carcinoma. Poor prognosis types ( $\leq 50 \%$ 10-year survival) includes ductal NST, solid lobular, mixed ductal and lobular carcinoma.

from 160 tumours could not be included in the study because of lack of tumour in the arrayed sample (due to sampling error or previous sectioning).

This is a well characterized series of primary operable breast cancer treated in a uniform manner and has been used to study a wide range of potential prognostic factors and markers including CD59, ${ }^{16} \mathrm{CD}^{17} 5^{17}$ and CD46 expression. ${ }^{18}$ Tumour characteristics, including histological grade,${ }^{19}$ tumour type, ${ }^{20}$ vascular invasion, ${ }^{21}$ menopausal status, ${ }^{22}$ tumour size, lymph node stage and Nottingham Prognostic Index ${ }^{23}$ are assessed routinely and recorded in a database. The Nottingham Prognostic Index (NPI) score was calculated for each patient based on the following equation: NPI $=$ $0.2 \times$ tumour size $(\mathrm{cm})+$ grade $(1-3)+$ lymph node stage $(1-3)$. This index predicts survival of patients with invasive breast cancer and is utilised clinically in 3 groups: good (NPI $\leq 3.4$ ), moderate $(3.41<\mathrm{NPI} \leq 5.4)$ or poor (NPI $>5.4)$ prognosis according to the score obtained.

\section{Antibodies}

The mouse mAb HC10 (provided by Professor H. Ploegh, Harvard Medical School, USA) recognizes free (non ligand associated/non- $\mathrm{B}_{2} \mathrm{~m}$ associated) human HLA Class I heavy chains with preferential binding to HLA-B and HLA-C alleles. ${ }^{24}$ The antiheavy chain mAb HC10 (IgG2a) reacts with denatured Class I antigens and showed strong reactivity in Western blots and conventional light microscopical analysis of formalin-fixed, paraffinembedded sections. This mAb precipitated 4 bands of molecular mass $78-105 \mathrm{kDa}$ and additional higher molecular mass material, seen by nonreducing SDS-PAGE, ${ }^{24,25}$ HC10 recognizes an epitope in the domain of unfolded HLA-B and - $C$ heavy chains that are not assembled with $\beta_{2} \mathrm{~m} .{ }^{26}$ In contrast $\beta_{2} \mathrm{~m}$ is essential for the structural stability and optimal function of Class I molecule, ${ }^{27}$ and is invariant and therefore independent of allelic variants. ${ }^{3,14,28}$ The polyclonal rabbit-anti- $\beta_{2}$-microglobulin (Dako, Cambridge, Ely, $\mathrm{UK}$ ) recognizes the light chain of MHC Class I molecule. 

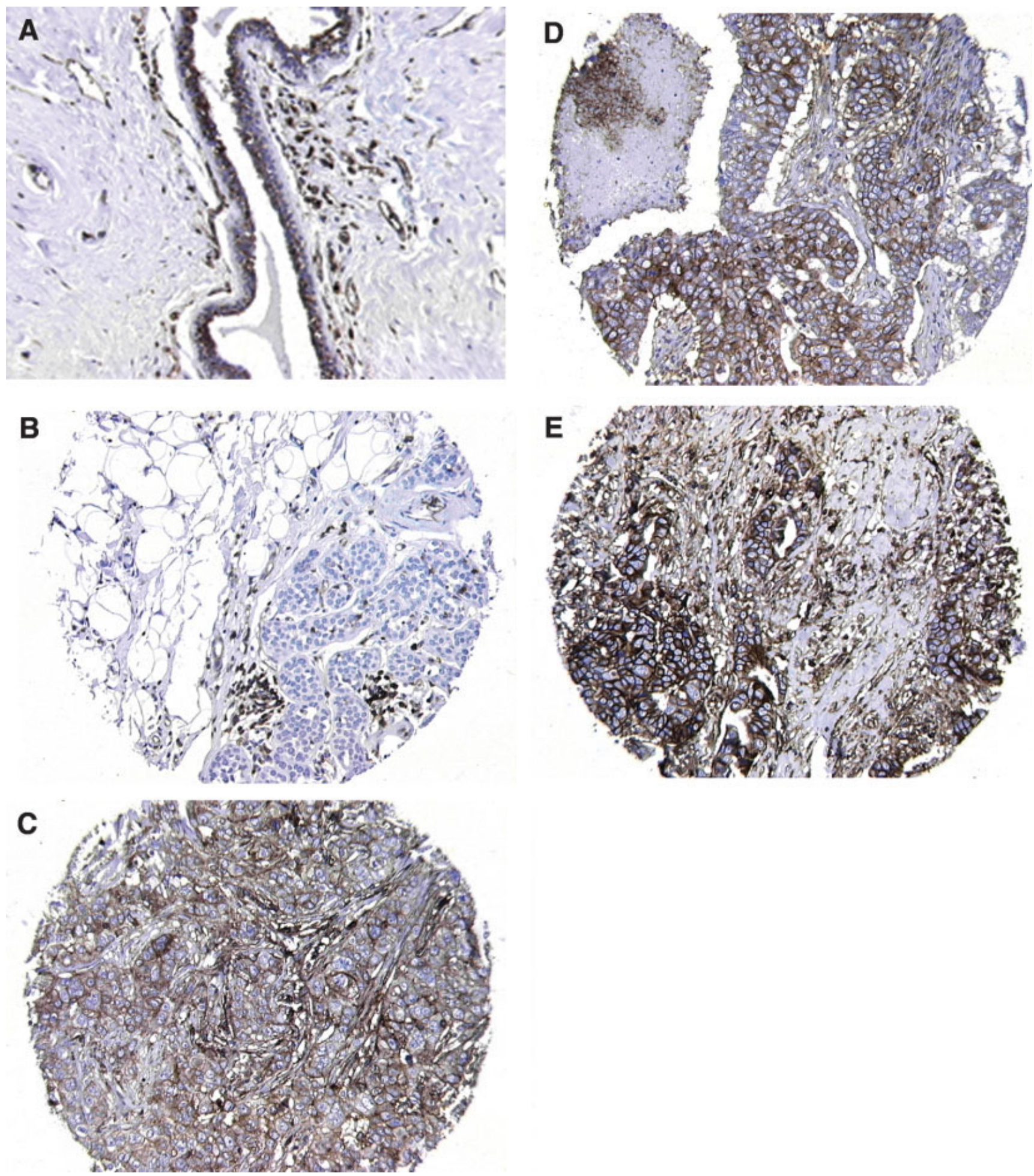

FigURE 1 - HLA heavy chain (HC10) expression. Immunohistochemical detection of HLA Class I heavy chain (HC10) in normal mammary epithelium and invasive carcinoma. (a) Normal epithelium of ducts and inflammatory cells consistently express HLA. (b) Lack of staining of tumour cells with strong staining of lymphocytes. $(c)$ weak and $(d)$ moderate staining of HC10. (e) Strong staining of invasive breast tumours.

\section{Immunohistochemistry}

Sections $4-\mu \mathrm{m}$ thick were cut and stained using a standard avidin-biotin complex method as described previously. ${ }^{17}$ Microwave pre-treatment was carried out in citrate buffer $(\mathrm{pH}=6.0) 10 \mathrm{~min}$ at high power followed by $10 \mathrm{~min}$ at low power to retrieve antige- nicity for staining of sections with $\mathrm{HC} 10$, whereas no pre-treatment was needed for staining of $\beta_{2} \mathrm{~m}$, based on manufacturer's recommendations. The primary antibodies were incubated on the slides for $1 \mathrm{hr}$ with the optimal dilution found to be 1:200 (HC10) and $1: 3,000\left(\right.$ anti- $\left.\beta_{2} \mathrm{~m}\right)$. 
Negative controls, consisting of normal swine serum (NSS) (Harlan Sera Lab, UK) instead of primary antibody, confirmed the specificity of the staining. Breast tumours that were associated strongly MHC Class I immunopositive inflammatory cells were used as internal positive control.

Many studies have shown that, contrary to expectations, tissue heterogeneity does not negatively influence the predictive power of the TMA results. ${ }^{29,30}$ To assess heterogeneity of the immunoreactivity with $\mathrm{HC} 10$, a pilot study of 20 cases were examined on full size tissue sections. A comparison of tissue array and original full size tissues showed similarity in intensity and the area of positive of staining.

TABLE II - INTENSITY OF EXPRESSION OF HLA CLASS I HEAVY AND LIGHT CHAINS

\begin{tabular}{lcc}
\hline \multirow{2}{*}{ Immunohistochemical score } & \multicolumn{2}{c}{$\%$ Tumours $(n)$} \\
\cline { 2 - 3 } & $\mathrm{HC} 10$ & Anti- $\beta_{2} \mathrm{~m} \mathrm{Ab}$ \\
\hline None & $47(206)$ & $39(167)$ \\
Weak $(+)$ & $34(150)$ & $36(153)$ \\
Moderate $(++)$ & $11(48)$ & $16(66)$ \\
Strong $(+++)$ & $8(35)$ & $9(38)$ \\
Total $(n)$ & 439 & 424 \\
\hline
\end{tabular}

Significant association was found between expression of $\mathrm{HC} 10$ and anti- $\beta_{2} \mathrm{~m}(p$-value $=0.001)$.

\section{Evaluation of immunostaining}

All of immunostained tissue arrays were evaluated using a semi-quantitative system by one author (Z.M.) in a coded manner without knowledge of the clinical and pathological parameters of the patients. The obtained results were confirmed by 2 observers (Z.M. and S.E.P.) using a multi-headed microscope and, in difficult cases, a consensus was achieved. The intensity of the staining was scored on a scale as 0 (absent), 1 (weak), 2 (moderate) or 3 (strong). The percentage of tumour cells showing positive staining was also assessed semi-quantitatively as $1(<25 \%), 2(25-50 \%), 3$ $(51-75 \%)$ or $4(>75 \%)$. In addition the histochemical score $(\mathrm{H}$ score) of immunoreactivity was obtained by multiplying the intensity and percentage scores. ${ }^{31}$ The histochemical score were subgrouped into 3 groups of equal range for analysis and a score of $<100$ was considered weak, $100-200$ was moderate and 201-300 was strong.

\section{Statistical analysis}

Statistical analysis of data was carried out using the SPSS package (version 11 for Windows, Chicago, IL). The significance of associations was determined by means of the Pearson $R$-test or Pearson $\chi^{2}$ test. In survival analysis, Kaplan-Meier curves were derived and the statistical significance of differences between the survival of groups with different HLA Class I expression was determined using the log-rank test. Survival was censored if the patients were still alive or died from other causes. Cox regres-
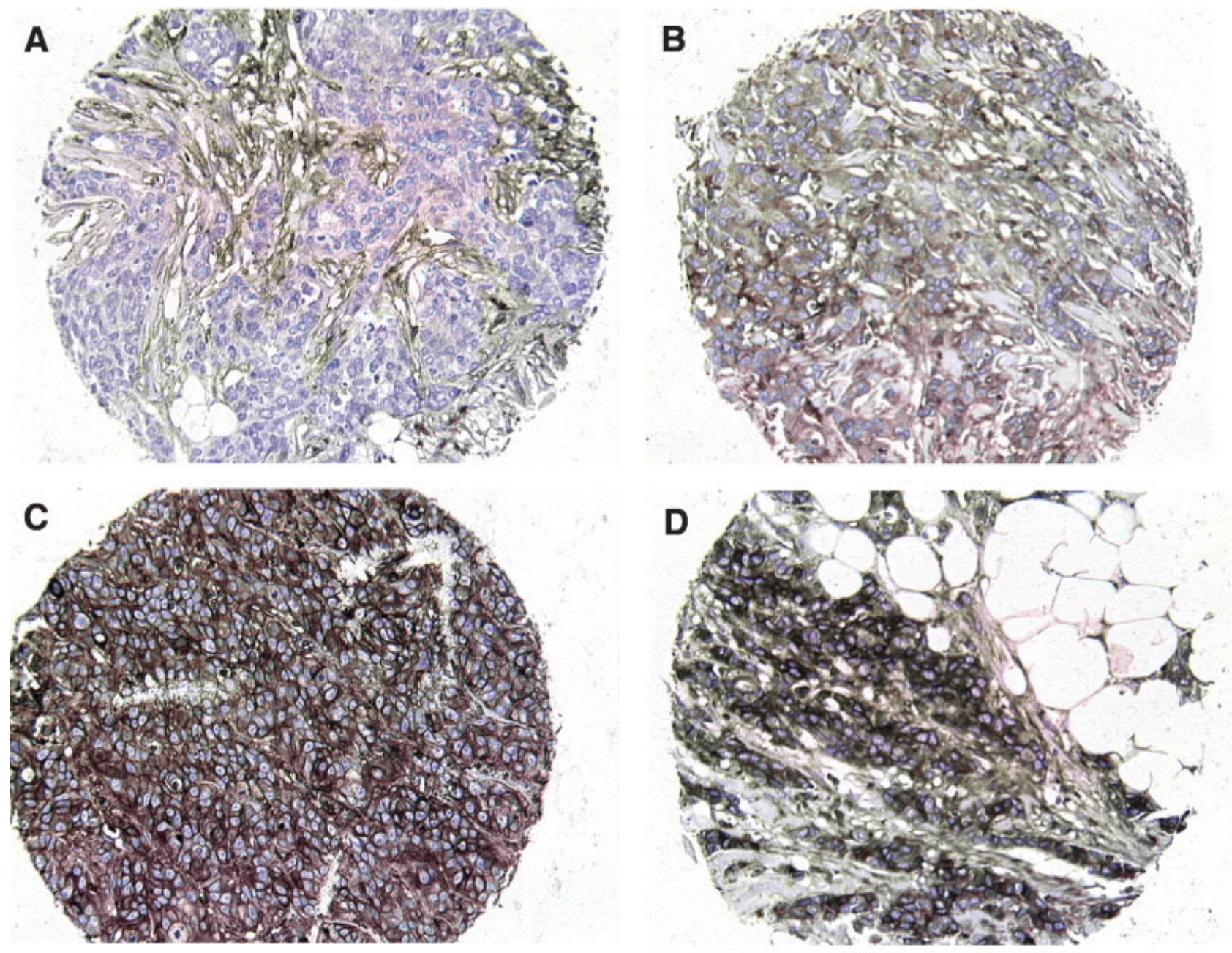

FigURE $2-\beta_{2}$-Microglobulin expression in invasive breast carcinoma. (a) No staining of tumour cells. (b) Weak and (c) moderate staining of breast carcinomas with $\beta_{2}-\mathrm{m}$. (d) Strong staining of invasive breast tumours. 
TABLE III - PERCENTAGE OF HLA CLASS I HEAVY AND LIGHT CHAINS POSITIVE TUMOUR CELLS

\begin{tabular}{lcc}
\hline \multirow{2}{*}{$\%$ HLA positive cells classified in 4 groups } & \multicolumn{2}{c}{$\%$ Tumours (n) } \\
\cline { 2 - 3 } & $\mathrm{HC} 10$ & Anti- $\beta_{2} \mathrm{~m} \mathrm{Ab}$ \\
\hline None & $47(206)$ & $39(167)$ \\
$<25 \%$ positive & $26(115)$ & $16(66)$ \\
$25-50 \%$ positive & $8(33)$ & $15(63)$ \\
$51-75 \%$ cells & $10(44)$ & $19(79)$ \\
$>75 \%$ cells & $9(41)$ & $11(49)$ \\
Total $(n)$ & 439 & 424 \\
\hline
\end{tabular}

Significant association was found between proportion of tumour cells stained with $\mathrm{HC} 10$ and anti- $\beta_{2} \mathrm{~m}(p$-value $=0.001)$.

sion analysis was used for multivariate analysis to allow the comparison of the effects of several different factors on survival. $p$-values $<0.05$ were identified as statistically significant.

\section{Results \\ Co-expression of MHC Class I light and heavy chains in breast carcinomas}

Only 439 of 539 arrayed samples contained sufficient tumour cells for assessment by $\mathrm{HC} 10$, whereas for $\beta_{2} \mathrm{~m}$ staining fewer samples (424/539) contained adequate tumour cells. Difference in number of cases in 2 series is due to tissue damage, either tissue loss or inadequate tumour tissue, a problem associated with tissue microarrays. Samples (113 of 539) contained stroma and inflammatory infiltrating cells. Inflammatory cells including lymphocytes, exhibited strong positive staining indicating the success of the immunohistochemical technique (Fig. 1a). Non-malignant breast tissues adjacent to carcinoma often showed strong expression of HLA heavy chain (Fig. $1 a$ ) as well as $\beta_{2} \mathrm{~m}$, however, considerable variations occurred in breast carcinomas. Forty-seven percent (206 of 439) breast carcinomas were considered negative for $\mathrm{HC} 10,45 \%$ (198) showed a reduction in the level of expression (34\% weak and $11 \%$ moderate staining), whereas only 35 $(8 \%)$ of breast tumours exhibited strong immunoreactivity in the cell membrane (Table II, Fig. $1 b-e)$. Similarly, 39\% $(n=167)$ of tumours lost $\beta_{2} \mathrm{~m}$ in the cell surface, $52 \%$ exhibited a reduction (36\% weak and $16 \%$ moderate), whereas only $9 \%(n=38)$ of tumours showed strong intensity (Table II, Fig. $2 a-d$ ). Expression of $\mathrm{HC} 10$ and $\beta_{2} \mathrm{~m}$ in the strong positive tumours was usually more intense than the adjacent non-malignant epithelium. Moreover, variable percentage of positive tumour cells was observed among 239 breast carcinomas detected with $\mathrm{HC} 10,115$ (26\%) showed $<25 \%$ positive tumour cells, whereas $9 \%$ (41) of cases showed extensive expression of $\mathrm{HC} 10$ ( $>75 \%$ positive tumour cells; Table III). In the same way, among 257 breast tumours detected with $\beta_{2} \mathrm{~m}, 16 \%$ (66) showed $<25 \%$ positive tumour cells, whereas $11 \%$ (49) of cases showed extensive expression ( $>75 \%$ positive tumour cells; Table III).

A significant association was found between $\mathrm{HC} 10$ staining and $\beta_{2} \mathrm{~m}$ staining $(p<0.001)$ for intensity and percentage. From 423 tumours analysed independently only $3 \%$ of $\beta_{2} \mathrm{~m}$ negative tumours stained positive for HLA Class I heavy chains (Tables II,III).

Association of MHC Class I light and heavy chains expression with clinicopathological characteristics

The association between expression of MHC Class I (HC10 and $\beta_{2} \mathrm{~m}$ ) and different prognostic parameters (histological grade, tumour type, vascular invasion, lymph node stage, tumour size and Nottingham Prognostic Index), patient characteristics (age and menopausal status) and outcome (overall survival and development of distant metastases, local and regional recurrence) was investigated in breast carcinomas (Table I).
TABLE IV - ASSOCIATION BETWEEN INTENSITY OF HLA HEAVY CHAIN (HC10) EXPRESSION AND HISTOLOGICAL GRADE, DISTANT METASTASIS, REGIONAL RECURRENCE, NOTTINGHAM PROGNOSTIC INDEX AND TUMOUR TYPE (PEARSON $\chi^{2}$ )

\begin{tabular}{|c|c|c|c|c|c|c|}
\hline \multirow{2}{*}{ Prognostic factors } & \multirow{2}{*}{$n$} & \multicolumn{4}{|c|}{ Intensity of $\mathrm{HC} 10$ expression (\%) } & \multirow{2}{*}{$p$-value } \\
\hline & & None & Weak & Moderate & Strong & \\
\hline \multicolumn{7}{|c|}{ Histological grade } \\
\hline Grade 1 & 90 & $58(64)$ & $26(29)$ & $4(5)$ & $2(2)$ & \multirow{3}{*}{$<0.001$} \\
\hline Grade 2 & 151 & $84(56)$ & $49(32)$ & $11(7)$ & $7(5)$ & \\
\hline Grade 3 & 196 & $64(33)$ & $73(37)$ & $33(17)$ & $26(13)$ & \\
\hline \multicolumn{7}{|c|}{ Distant metastasis } \\
\hline Absent & 384 & $190(50)$ & $124(32)$ & $42(11)$ & $28(7)$ & \multirow{2}{*}{0.027} \\
\hline Present & 55 & $16(29)$ & $26(47)$ & $6(11)$ & $7(13)$ & \\
\hline \multicolumn{7}{|c|}{ Regional recurrence } \\
\hline Absent & 401 & $197(49)$ & $134(33)$ & $42(11)$ & $28(7)$ & \multirow{2}{*}{0.007} \\
\hline Present & 38 & $9(24)$ & $16(42)$ & $6(16)$ & $7(18)$ & \\
\hline \multicolumn{7}{|l|}{ NPI } \\
\hline Good & 148 & $90(61)$ & $48(32)$ & $6(4)$ & $4(3)$ & \multirow{3}{*}{$<0.001$} \\
\hline Moderate & 233 & $94(40)$ & $83(36)$ & $34(15)$ & $22(9)$ & \\
\hline Poor & 47 & $22(47)$ & $12(25)$ & $7(15)$ & $6(13)$ & \\
\hline \multicolumn{7}{|l|}{ Tumour type } \\
\hline Excellent & 18 & $14(78)$ & $3(17)$ & & $1(5)$ & \multirow{4}{*}{$<0.001$} \\
\hline Good & 100 & $62(62)$ & $30(30)$ & $8(8)$ & & \\
\hline Moderate & 51 & $26(51)$ & $16(31)$ & $5(10)$ & $4(8)$ & \\
\hline Poor & 265 & $102(39)$ & $98(37)$ & $35(13)$ & $30(11)$ & \\
\hline
\end{tabular}

A positive relationship was found between the intensity of MHC Class I light and heavy chains expression and histological grade of invasive tumour $(p<0.001$, Table I); a high level of expression was more often found in histological Grade 3 tumours compared to Grade 1 lesions (Table IV). It was also found that expression of $\mathrm{HC} 10$ and $\beta_{2} \mathrm{~m}$ was related significantly to Nottingham Prognostic Index $(p<0.001$, Table I), i.e., loss of MHC Class I heavy chain was more often found in tumours from patients in the good prognosis group compared to poor prognosis group patients (Table IV).

Moreover, the intensity of MHC Class I heavy and light chains was associated with histological tumour type group $(p<0.001$, Table I), i.e., absent of staining was more often seen in excellent prognosis type tumours (tubulo-lobular, tubular, mucinous and invasive cribriform) compared to poor prognosis types (ductal/ NST, solid lobular, lobular mixed or mixed NST and lobular cancers; Table IV).

In particular, there was an association between intensity of MHC Class I expression and patient outcome, i.e., a strong intensity of HLA expression was correlated significantly with the development of distant metastasis ( $\mathrm{HC} 10$ and $\left.\beta_{2} \mathrm{~m}, p=0.02\right)$ and of regional recurrence (HC10: $p=0.007$ and $\beta_{2} \mathrm{~m}: p=0.017$; Table I). Similarly, a significant positive correlation was observed between the percentage of MHC Class I light and heavy chains positive tumour cells and histological grade $(p<0.001)$, NPI group (HC10: $p<0.001$ and $\beta_{2} \mathrm{~m}: p=0.003$ ), tumour type group $(p<0.001)$, development of distant metastasis (HC10: $p=0.045$ and $\beta_{2} \mathrm{~m}: p=0.032$ ) and regional recurrence (HC10: $p=0.018$ and $\beta_{2} \mathrm{~m}$ : 0.028; Table I).

In contrast, no association was demonstrated between expression of MHC Class I light and heavy chains on these invasive breast carcinomas and the absence or presence of vascular invasion, local recurrence, lymph node stage, menopausal status or patient age at time of diagnosis (Table I).

\section{Analysis of survival in relation to MHC Class I light and heavy chains}

Kaplan-Meier analysis on these series of breast cancer patients, with mean follow-up of 7 years, demonstrated significant differences in the overall survival between the patients group with com- 
A

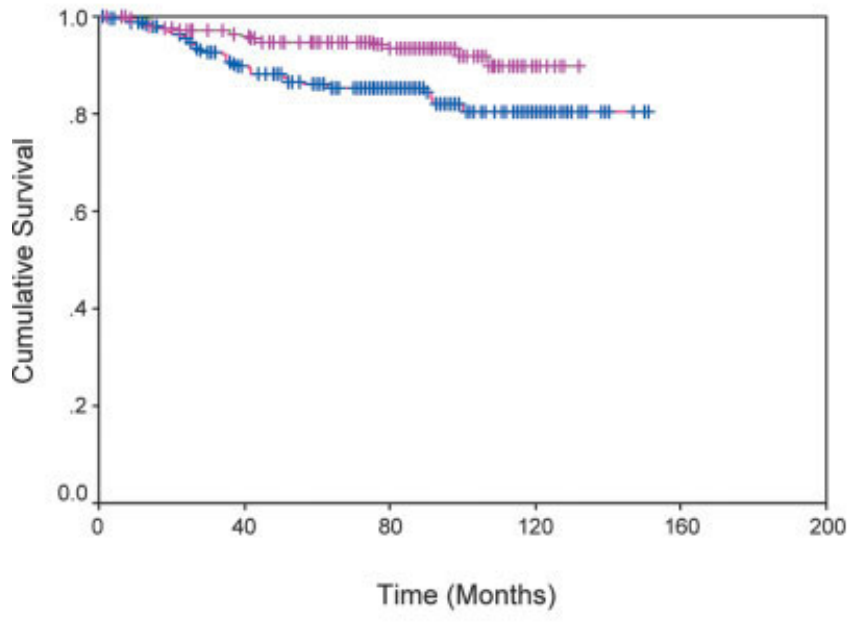

Log rank $P=0.004$

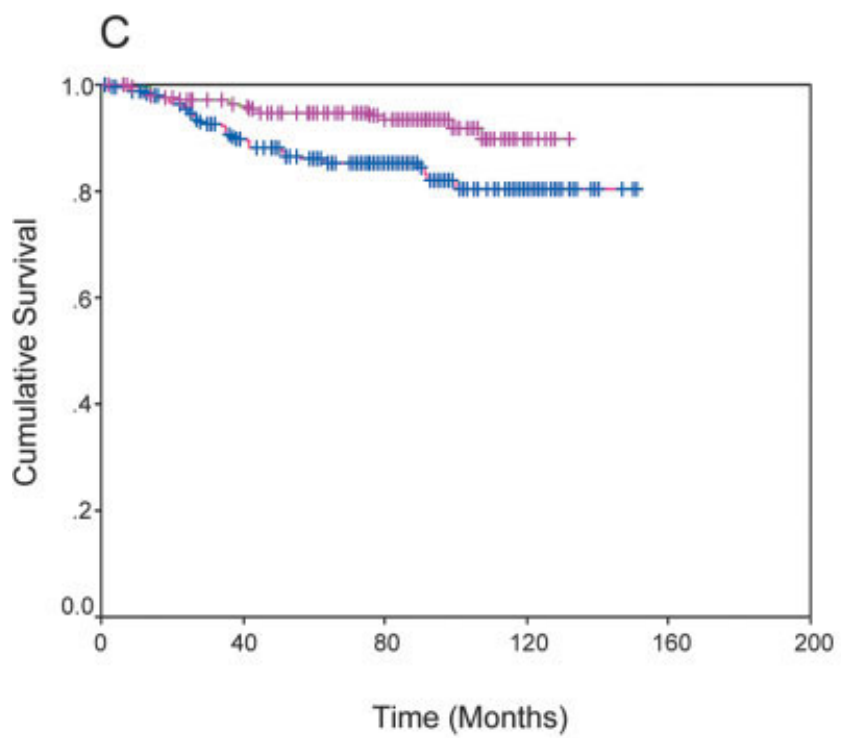

B

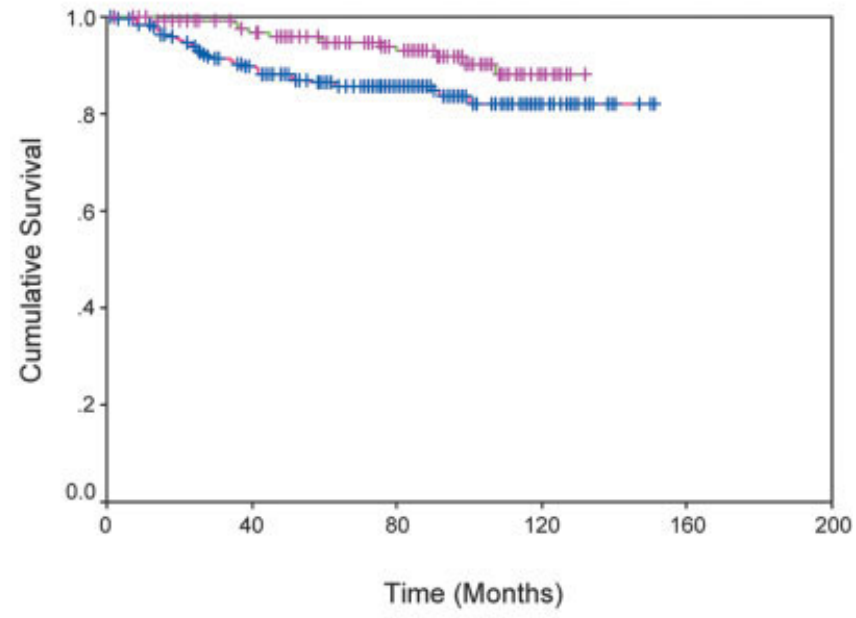

Log rank $P=0.021$

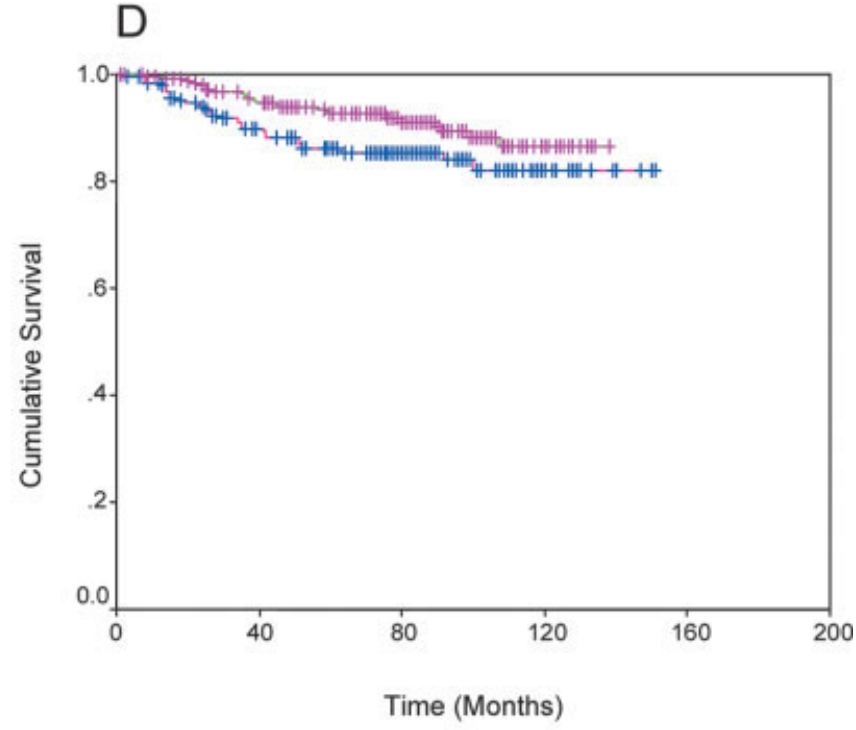

$\log$ rank $=0.072$

FIGURE 3 - HLA expression and overall survival. Kaplan-Meier analysis showing the overall survival of breast cancer patients according to the HLA staining with $\mathrm{HC} 10$ and $\beta_{2}$ microglobulin $(a, b)$ and the semi-quantitatively assessed percentage of positive cells $(c, d)$. Overall survival of HLA negative cells (no staining of $\mathrm{HC} 10$ and $\beta_{2}$ microglobulin) was better than that of positive tumours (weak, moderate or strong staining, $p$-values for $\mathrm{HC} 10$ and $\beta_{2}$ are 0.0047 and $\left.0.021 ; a, b\right)$. Similarly, patients with absent or a low percentage of $\mathrm{HC} 10$ positive cells $(<25 \%)$ showed significantly longer survival times than patients with $>25 \%$ positive tumour cells $(p=0.0043, c)$, whereas it was not significant for percentage of $\beta_{2}$ m positive cells $(d)$

plete loss of MHC Class I light and heavy chains (no staining) and MHC Class I light and heavy chains positive tumours (weak, moderate or strong staining, Log-rank test for $\mathrm{HC} 10$ and $\beta_{2} \mathrm{~m}$ : 0.0047 and 0.021 , Fig. $3 a, b)$. As can be seen in Figure $3 a, b$, patients whose breast tumours lost MHC Class I showed a more favourable outcome than those tumours with immunohistochemically detectable expression of MHC Class I. Similar results was found for the percentage of cells expressing $\mathrm{HC} 10$ and patient survival, indicating that the cumulative survival rate of the patients with absent or a low percentage of $\mathrm{HC} 10$ positive cells $(<25 \%)$ was significantly higher than that for patients with $>25 \%$ positive tumour cells $(p$ $=0.0047$, Fig. $3 c$ ). In contrast, there was no significant association between the percentage of cells expressing $\beta_{2} \mathrm{~m}$ and these groups of patients ( $p=0.072$, Fig. $3 d$ ). Briefly, patients with carcinomas exhibiting a lower level of HLA expression achieved longer survival times.

\section{Multivariate analysis}

To investigate whether HLA expression had independent prognostic significance, Cox multivariate regression analysis, including the parameters of tumour size, lymph node stage, grade and intensity of $\mathrm{HC} 10$ and $\beta_{2} \mathrm{~m}$ expression, was carried out. In this analysis, lymph node stage $(p<0.001)$, tumour grade $(p=$ $0.005)$ and intensity of MHC Class I light and heavy chains expression were shown to be independent prognostic factors predictive of overall survival ( $p$-values for $\mathrm{HC} 10$ and $\beta_{2} \mathrm{~m}$ are: 
TABLE V - MULTIVARIATE ANALYSIS INCLUDING TUMOUR SIZE, GRADE, STAGE, AND INTENSITY OR PERCENTAGE OF POSITIVE CELLS (HC10 AND B2M) FOR OVERALL SURVIVAL

\begin{tabular}{|c|c|c|c|c|}
\hline \multirow{2}{*}{ Prognostic factors } & \multicolumn{2}{|c|}{ Hazard ratio $(95 \% \mathrm{CI})$} & \multicolumn{2}{|c|}{$p$-value } \\
\hline & $\mathrm{HC} 10$ & Anti- $\beta_{2} \mathrm{~m} \mathrm{Ab}$ & $\mathrm{HC} 10$ & Anti- $\beta_{2} \mathrm{~m} \mathrm{Ab}$ \\
\hline Tumour size & $1.05(0.82-1.34)$ & $1.02(0.80-1.29)$ & 0.67 & 0.86 \\
\hline Grade & $8.15(1.91-34.74)$ & $7.72(1.82-32.70)$ & 0.005 & 0.005 \\
\hline Stage & $13.75(6.16-30.71)$ & $11.84(5.44-25.75)$ & $<0.001$ & $<0.001$ \\
\hline Intensity of expression ( $\mathrm{HC} 10$ and anti- $\left.\beta_{2} \mathrm{~m} \mathrm{Ab}\right)$ & $1.93(0.008-3.71)$ & $2.283(1.14-4.53)$ & 0.047 & 0.018 \\
\hline$\%$ Positive cells ( $\mathrm{HC} 10$ and anti- $\left.\beta_{2} \mathrm{~m} \mathrm{Ab}\right)$ & $1.93(0.008-3.71)$ & - & 0.047 & - \\
\hline
\end{tabular}

0.047 and 0.018$)$. The percentage of cells expressing $\beta_{2} \mathrm{~m}$ was also found to be of independent prognostic significance ( $p=$ 0.047, Table V).

\section{Discussion}

We found weak expression or absence of MHC Class I molecules in the majority of breast carcinomas studied. In $47 \%$ of primary breast carcinomas no staining for MHC Class I was observed, similarly lack of staining for $\beta_{2}$ m was observed in $39 \%$ of tumours. Importantly analysis of individual tumours indicated that concordant results were obtained using antibodies to either Class I heavy chain (HC10) or $\beta_{2} \mathrm{~m}$, with only $3 \%$ of $\beta_{2} \mathrm{~m}$ negative tumours showing any expression of MHC Class I heavy chain. Conversely only $8 \%$ of tumours stained positively for MHC Class I but were absent for $\beta_{2} \mathrm{~m}$ expression. This supports earlier studies on paraffin embedded breast carcinomas that showed a good correlation between $\beta_{2}$ m and heavy chain expression ${ }^{8}$ with only 4 of 56 (7\%) $\beta_{2}$ m negative tumours staining for cytoplasmic expression of free MHC Class I heavy chain. ${ }^{32}$ A similar lack of expression of HLA Class I has been reported in a range of tumours including breast carcinomas. $^{3,8-14,33}$

Although both haplotype loss and allelic loss of HLA can have profound consequences for $\mathrm{T}$ cell recognition, our study only addressed the issue of total HLA loss. There are several steps involved in HLA- Class I expression and any of these could potentially be defective leading to complete loss in tumour cells. Two types of defects, $(i)$ mutations in the HLA-Class I genes or abnormal regulation of their expression and (ii) abnormal antigen processing such as TAP (transporter associated with antigen processing) or tapasin loss have received the most attention. ${ }^{12}$ In a recent study on breast tumours it was shown by RT-PCR and biochemical analysis that loss of HLA Class I expression is associated predominantly with post-transcriptional regulation of $\beta_{2} \mathrm{~m}$. ${ }^{34}$ This may also be a result of dedifferentiation or oncogene expression.

Hormone receptor status has a high prognostic value in breast cancer and could possibly have an influence on MHC Class I expression as it can be induced on breast cancer cell lines by exposure to oestrogen. ${ }^{35}$ There was, however, no correlation with oestrogen receptor status and HLA expression in our study data (data not shown). There was a good correlation between histological grade, distant metastases, Nottingham Prognostic Index, tumour type and recurrence and the level of expression of MHC Class I heavy and light chains. Furthermore this was translated into a direct relationship between patient survival and HLA expression. These results were unexpected as previous studies had suggested that loss of Class I MHC expression could lead to escape from $\mathrm{T}$ cell recognition and a higher probability of disease recurrence. ${ }^{33}$ This correlation was only significant for node negative patients and did not correlate with any clinicopathological parameters in a much smaller series of breast tumours $(n=187)$ that only included infiltrating ductal or lobular carcinomas. Our study has utilised tissue microarrays that are constructed from small representative areas of tumour tissue from multiple blocks of 439 breast tumours of all types. Heterogeneity arising from this sampling has been shown to be overcome by staining a large number samples. ${ }^{29,30} \mathrm{We}$ also addressed this issue by staining of 20 original full size tissue sections and observed complete concordance with tissue array results. Several other studies have failed to show any correlation between HLA-expression and patient prognosis but most of these studies have analysed small numbers of breast tumours with short clinical follow up. This is the largest study of breast tumours with good long-term follow-up and shows that loss of MHC Class I expression is associated with a good prognosis. This may be correlated with the recent finding that MHC Class I expression is associated with expression of the proapoptotic bax gene and inversely correlated with expression of the anti-apoptotic bcl-2 gene. ${ }^{32}$ Loss of MHC Class I may therefore be associated with an increased resistance to apoptosis. Alternatively immune surveillance by $\mathrm{T}$ cells may result in tumour escape by downregulation of MHC molecules a process known as "immune editing." This loss of MHC I may make the tumours more susceptible to NK killing and result in a better prognostic outcome

Our study shows that on a large series of breast tumours with long-term clinical follow-up there is a selective loss of expression of MHC Class I heavy and light chains that is related to improved prognosis. This loss may be a consequence of dedifferentiation as expression correlated with tumour stage and grade although loss of MHC heavy and light chains was shown to be an independent prognostic factor. Alternatively it may be due to immunosurveillance that in some patients selects against the more aggressive tumours leaving the more indolent HLA negative tumours to grow through. The growth of these tumours may then be further controlled by NK cells. In contrast tumour cells may downregulate specific HLA alleles protecting them from specific $\mathrm{T}$ cell attack while not making then susceptible to NK recognition. This issue was not addressed in our study.

In conclusion, loss of MHC heavy and light chains has been shown to be an independent indicator of good prognosis in breast tumours. It could be added to the other independent prognostic factors to help further stratify patients for adjuvant therapy. Patients expressing HLA could be candidates for aggressive chemotherapy as they have a poor predicted outcome. Alternatively they may be candidates for cancer vaccines that stimulate new cytotoxic $\mathrm{T}$ cell responses. In contrast patients lacking Class I HLA may be appropriate for monoclonal antibody therapy such as Herceptin as lack of HLA would enhance NK killing by antibody dependent cellular cytotoxicity (ADCC).

\section{Acknowledgements}

We thank Professor H.L Ploegh for providing the HC10 antibody and J. Ronan for helpful comments.

\section{References}

1. Ochsenbein AF, Klenerman P, Karrer U, Ludewig B, Pericin M, Hengartner $\mathrm{H}$, Zinkernagel RM. Immune surveillance against a solid tumor fails because of immunological ignorance. Proc Natl Acad Sci USA 1999;96:2233-8.
2. Dunn GP, Old LJ, Schreiber RD. The three Es of cancer immuno editing. Annu Rev Immunol 2004;22:329-60.

3. Garrido F, Ruiz-Cabello F, Cabrera T, Perez-Villar JJ, Lopez-Botet M, Duggan-Keen M, Stern PL. Implications for immunosurveillance 
of altered HLA Class I phenotypes in human tumours. Immunol Today 1997;18:89-95.

4. Fleming KA, McMichael A, Morton JA, Woods J, McGee JO. Distribution of HLA class 1 antigens in normal human tissue and in mammary cancer. J Clin Pathol 1981;34:779-84.

5. Natali PG, Giacomini P, Bigotti A, Imai K, Nicotra MR, Ng AK, Ferrone S. Heterogeneity in the expression of HLA and tumor-associated antigens by surgically removed and cultured breast carcinoma cells. Cancer Res 1983;43:660-8.

6. Perez M, Cabrera T, Lopez Nevot MA, Gomez M, Peran F, RuizCabello F, Garrido F. Heterogeneity of the expression of Class I and II HLA antigens in human breast carcinoma. J Immunogenet 1986;13: 247-53.

7. Wintzer HO, Benzing M, von Kleist S. Lacking prognostic significance of beta 2-microglobulin, MHC Class I and Class II antigen expression in breast carcinomas. Br J Cancer 1990;62:289-95.

8. Concha A, Cabrera T, Ruiz-Cabello F, Garrido F. Can the HLA phenotype be used as a prognostic factor in breast carcinomas? Int J Cancer Suppl 1991;6:146-54.

9. Concha A, Esteban F, Cabrera T, Ruiz-Cabello F, Garrido F. Tumor aggressiveness and MHC Class I and II antigens in laryngeal and breast cancer. Semin Cancer Biol 1991;2:47-54.

10. Klein G, Klein E. Evaluation of tumours and the impact of molecular oncology. Nature 1985;315:190-95.

11. Garrido F, Cabrera T, Concha A, Glew S, Ruiz-Cabello F, Stern PL. Natural history of HLA expression during tumour development. Immunol Today 1993;14:491-9.

12. Hicklin DJ, Marincola FM, Ferrone S. HLA Class I antigen downregulation in human cancers: T-cell immunotherapy revives an old story. Mol Med Today 1999:5:178-86.

13. Eyal A, Levin I, Segal S, Levi I, Klein B, Kuperman O. Variation of HLA-ABC surface antigen expression on adenocarcinoma of the colon in correlation with the degree of differentiation. Nat Immun Cell Growth Regul 1990;9:222-7.

14. Levin I, Klein T, Goldstein J, Kuperman O, Kanetti J, Klein B. Expression of Class I histocompatibility antigens in transitional cell carcinoma of the urinary bladder in relation to survival. Cancer 1991; $68: 2591-4$.

15. Kononen J, Bubendorf L, Kallioniemi A, Barlund M, Schraml P, Leighton S, Torhorst J, Mihatsch MJ, Sauter G, Kallioniemi OP. Tissue microarrays for high-throughput molecular profiling of tumor specimens. Nat Med 1998;4:844-7.

16. Madjd Z, Pinder SE, Paish C, Ellis IO, Carmichael J, Durrant LG. Loss of CD59 expression in breast tumours correlates with poor survival. J Pathol 2003;200:633-9.

17. Madjd Z, Durrant LG, Bradley R, Spendlove I, Ellis IO, Pinder SE. Loss of CD55 is associated with aggressive breast tumors. Clin Cancer Res 2004;10:2797-803

18. Madjd Z, Durrant LG, Pinder SE, Ellis IO, Ronan J, Lewis S, Rushmere NK, Spendlove I. Do poor-prognosis breast tumours express membrane cofactor proteins (CD46)? Cancer Immunol Immunother 2005;54:149-56.

19. Elston CW, Ellis IO. Pathological prognostic factors in breast cancer. I. The value of histological grade in breast cancer: experience from a large study with long-term follow-up. Histopathology 1991;19:40310.

20. Ellis IO, Galea M, Broughton N, Locker A, Blamey RW, Elston CW. Pathological prognostic factors in breast cancer. II. Histological type. Relationship with survival in a large study with long-term follow-up. Histopathology 1992;20:479-89.
21. Pinder SE, Ellis IO, Galea M, O'Rouke S, Blamey RW, Elston CW. Pathological prognostic factors in breast cancer. III. Vascular invasion: relationship with recurrence and survival in a large study with long-term follow-up. Histopathology 1994;24:41-7.

22. Todd JH, Dowle C, Williams MR, Elston CW, Ellis IO, Hinton CP, Blamey RW, Haybittle JL. Confirmation of a prognostic index in primary breast cancer. Br J Cancer 1987;56:489-92.

23. Galea MH, Blamey RW, Elston CE, Ellis IO. The Nottingham Prognostic Index in primary breast cancer. Breast Cancer Res Treat 1992; 22:207-19.

24. Stam NJ, Vroom TM, Peters PJ, Pastoors EB, Ploegh HL. HLA-Aand HLA-B-specific monoclonal antibodies reactive with free heavy chains in western blots, in formalin-fixed, paraffin-embedded tissue sections and in cryo-immuno-electron microscopy. Int Immunol 1990;2:113-25.

25. Stam NJ, Spits H, Ploegh HL. Monoclonal antibodies raised against denatured HLA-B locus heavy chains permit biochemical characterization of certain HLA-C locus products. J Immunol 1986;137:2299306.

26. Perosa F, Luccarelli G, Prete M, Favoino E, Ferrone S, Dammacco F. Beta 2-microglobulin-free HLA Class I heavy chain epitope mimicry by monoclonal antibody HC-10-specific peptide. J Immunol 2003; 171:1918-26.

27. Pedersen LO, Hansen AS, Olsen AC, Gerwien J, Nissen MH, Buus S. The interaction between beta 2-microglobulin (beta $2 \mathrm{~m}$ ) and purified class-I major histocompatibility (MHC) antigen. Scand J Immunol 1994;39:64-72.

28. Petersen BL, Petersen CL, Braendstrup O, Mouritsen S, Engel AM, Svane IM, Werdelin O. Expression of beta 2-microglobulin by premalignant epithelium. APMIS 1993;101:529-36.

29. Bubendorf L, Nocito A, Moch H, Sauter G. Tissue microarray (TMA) technology: miniaturized pathology archives for high-throughput in situ studies. J Pathol 2001;195:72-9.

30. Torhorst J, Bucher C, Kononen J, Haas P, Zuber M, Kochli OR, Mross F, Dieterich H, Moch H, Mihatsch M, Kallioniemi OP, Sauter G. Tissue microarrays for rapid linking of molecular changes to clinical endpoints. Am J Pathol 2001;159:2249-56.

31. McCarty KS, Jr., Miller LS, Cox EB, Konrath J, McCarty KS, Sr. Estrogen receptor analyses. Correlation of biochemical and immunohistochemical methods using monoclonal antireceptor antibodies. Arch Pathol Lab Med 1985;109:716-21.

32. Redondo M, Garcia J, Villar E, Rodrigo I, Perea-Milla E, Serrano A, Morell M. Major histocompatibility complex status in breast carcinogenesis and relationship to apoptosis. Hum Pathol 2003;34:1283-9.

33. Gudmundsdottir I, Gunnlaugur Jonasson J, Sigurdsson H, Olafsdottir K, Tryggvadottir L, Ogmundsdottir HM. Altered expression of HLA Class I antigens in breast cancer: association with prognosis. Int $\mathrm{J}$ Cancer 2000;89:500-5.

34. Palmisano GL, Pistillo MP, Capanni P, Pera C, Nicolo G, Salvi S, Perdelli L, Pasciucco G, Ferrara GB. Investigation of HLA Class I downregulation in breast cancer by RT-PCR. Hum Immunol 2001;62:133-9.

35. Rodriguez F, Peran F, Garrido F, Ruiz-Cabello F. Upmodulation by estrogen of HLA Class I expression in breast tumor cell lines. Immunogenetics 1994:39:161-7.

36. Pereira H, Pinder SE, Sibbering DM, Galea MH, Elston CW, Blamey RW, Robertson JF, Ellis IO. Pathological prognostic factors in breast cancer. IV: Should you be a typer or a grader? A comparative study of two histological prognostic features in operable breast carcinoma. Histopathology 1995;27:219-26. 